\title{
Tanshinone IIA inhibits the growth of pancreatic cancer BxPC-3 cells by decreasing protein expression of TCTP, MCL-1 and Bcl-xL
}

\author{
CHENG-YEN HUANG ${ }^{1,2^{*}}$, TSUNG-LANG CHIU ${ }^{3,4^{*}}$, SHOU-JEN KUO $^{1}$, \\ SU-YU CHIEN ${ }^{5}$, DAR-REN CHEN ${ }^{1,6}$ and CHIN-CHENG SU $\mathrm{U}^{1,2,6,7}$ \\ ${ }^{1}$ Department of Surgery; ${ }^{2}$ Tumor Research Center of Integrative Medicine, Changhua Christian Hospital, Changhua 500-06; \\ ${ }^{3}$ Tzu-Chi University; ${ }^{4}$ Neuromedical Scientific Center, Buddhist Tzu-Chi General Hospital, Hualien 970; \\ ${ }^{5}$ Department of Pharmacy; ${ }^{6}$ Comprehensive Breast Cancer Center, Changhua Christian Hospital, Changhua 500-06; \\ ${ }^{7}$ School of Chinese Medicine, College of Chinese Medicine, China Medical University, Taichung 40402, Taiwan, R.O.C.
}

Received October 9, 2012; Accepted January 15, 2013

DOI: $10.3892 / \mathrm{mmr} .2013 .1290$

\begin{abstract}
Pancreatic cancer remains a challenging disease worldwide. Tanshinone IIA (Tan-IIA) is one of the active constituents of Danshen (Radix Salviae miltiorrhizae). Tan-IIA has been hypothesized to inhibit numerous human cancer cells by various molecular mechanisms. However, the efficacy and molecular mechanism of Tan-IIA action in pancreatic cancer has not been well studied. In the present study, the cytotoxicity of Tan-IIA in human pancreatic cancer BxPC-3 cells was evaluated by MTT assay. Cell cycle analysis of BxPC-3 cells treated with Tan-IIA was performed by flow cytometry (FACS). Protein expression levels of TCTP, MCL-1, Bcl-xL, Bax and Caspase-3 in BxPC-3 cells were measured by western blot analysis. The results revealed that Tan-IIA inhibited BxPC-3 cells in a time- and dose-dependent manner. FACS analysis demonstrated that Tan-IIA increases the rate of sub- $\mathrm{G}_{1}$ phase. BxPC-3 cells treated with Tan-IIA were identified to upregulate protein expression of Bax and Caspase-3 and downregulate expression of TCTP, MCL-1 and Bcl-xL. These results indicate that Tan-IIA may inhibit BxPC-3 human pancreatic cancer cells through the induction of apoptosis by decreasing protein expression of TCTP, MCL-1 and Bcl-xL and increasing Bax expression in vitro. The chemotherapeutic potential of Tan-IIA for human pancreatic cancer warrants further study.
\end{abstract}

\section{Introduction}

In 2008, the number of new cases of pancreatic cancer in developed countries was ranked ninth worldwide in males

Correspondence to: Dr Chin-Cheng Su, Department of Surgery, Comprehensive Breast Cancer Center, Tumor Research Center of Integrative Medicine, Changhua Christian Hospital, 135 Nan-Hsiao Street, Changhua, Changhua 500-06, Taiwan, R.O.C.

E-mail:succ.maeva@msa.hinet.net

*Contributed equally

Key words: tanshinone IIA, BxPC-3 cells, TCTP, MCL-1 and females, however, the estimated number of mortalities was ranked fourth and fifth worldwide in females and males, respectively (1). Pancreatic cancer remains a challenging disease worldwide. In 2012, the mortality of pancreatic cancer continues to increase. Pancreatic cancer is the fourth leading cause of cancer mortality in the USA (2). These statistics indicate that current chemotherapeutic medicines are unsatisfactory and highlight the requirement for identification of new treatments. Traditional herbs are widely accepted as a valid method of treatment of various forms of human cancer and a considerable effort to develop alternative medicines is currently underway (3). Tanshinone IIA (Tan-IIA; $\mathrm{C}_{19} \mathrm{H}_{18} \mathrm{O}_{3}$ ) is one of the active constituents of Danshen $(4,5)$. Tan-IIA is toxic to numerous human cancer cells, including Colo205 colon cancer (6), MDA-MB-231 breast cancer (7), A-549 non-small cell lung cancer (8), H-146 small cell lung cancer (9) and Hep-J5 hepatocellular carcinoma cells (10). Previously, it was reported that Tan-IIA has cytotoxic effects in MIAPaCa-2 human pancreatic tumor cell lines as the half-maximal inhibitory concentration $\left(\mathrm{IC}_{50}\right)$ was calculated as $1.9 \mu \mathrm{M}$ (11). However, the mechanism has not been established. In the present study, the efficacy and molecular mechanisms of Tan-IIA in human pancreatic cancer BxPC-3 cells was investigated.

\section{Materials and methods}

Chemicals and reagents. Tan-IIA was purchased from Sigma-Aldrich (no. 568-72-9; St. Louis, MO, USA). The BxPC-3 human pancreatic cancer cell line (BCRC no. 60283) was obtained from the Food Industry Research and Development Institute (Hsinchu, Taiwan). 3-(4,5-Dimethylthiazol-2-y1)-2,5-diphenyltetrazolium bromide (MTT), sodium deoxycholate, leupeptin, Triton X-100, Tris- $\mathrm{HCl}$, ribonuclease-A, sodium orthovanadate, sodium pyruvate, HEPES, RPMI-1640 medium, trypsin-EDTA, mouse anti- $\beta$-actin and penicillin-streptomycin were obtained from Sigma-Aldrich. Dimethyl sulfoxide (DMSO), potassium phosphates and TE buffer were purchased from Merck Co. (Darmstadt, Germany). Fetal bovine serum (FBS) and glutamine were obtained from Gibco-BRL (Grand Island, NY, USA). Buffer (10X TG-SDS), Tween-20 and glycine 
were obtained from Amresco LLC (St. Louis, MO, USA). BioMax film was obtained from Kodak (Rochester, NY, USA). Antibodies against Bax (\#2774), Bcl-xL (\#2764), Bcl-2 (\#2872), MCL-1 (\#2764) and TCTP (\#2764) were obtained from Cell Signaling Technology, Inc. (Danvers, MA, USA). Other materials and reagents not specified were obtained from Sigma-Aldrich or Merck Co.

Cell culture. BxPC-3 cells were maintained in RPMI-1640 medium containing $10 \% \mathrm{FBS}, 1 \%$ penicillin-streptomycin $\left(10,000 \mathrm{U} / \mathrm{ml}\right.$ penicillin and $10 \mathrm{mg} / \mathrm{ml}$ streptomycin) at $37^{\circ} \mathrm{C}$ in a humidified atmosphere containing $5 \% \mathrm{CO}_{2}$.

Cytotoxicity assay. Cells were plated in 96-well plates at a density of $1 \times 10^{4}$ cells/well for $16 \mathrm{~h}$. Following this, the cells were treated with various concentrations of Tan-IIA for 24 and $48 \mathrm{~h}$. Following this, cells were incubated with $1 \mathrm{mg} / \mathrm{ml} \mathrm{MTT}$ in fresh complete RPMI-1640 medium for $2 \mathrm{~h}$. The surviving cells converted MTT to formazan by forming a blue-purple color when dissolved in DMSO. The intensity of formazan was measured at $590 \mathrm{~nm}$ using a microplate reader. The relative percentage of cell viability was calculated by dividing the absorbance of treated cells by that of the control in each experiment.

Cell cycle analysis. Cell cycle progression following treatment with Tan-IIA was measured by flow cytometry. The cells were plated at a density of $1 \times 10^{6} \mathrm{cells} / 6-\mathrm{cm}$ dish in complete medium for $16 \mathrm{~h}$. Following treatment, the cells were collected and fixed with ice-cold $70 \%$ ethanol overnight at $-20^{\circ} \mathrm{C}$. Cells were centrifuged and the cell pellets were treated with $4 \mu \mathrm{g} / \mathrm{ml}$ PI solutions containing $100 \mu \mathrm{g} / \mathrm{ml}$ RNase at $37^{\circ} \mathrm{C}$ for $30 \mathrm{~min}$. Subsequently, samples were analyzed in a Cytomics ${ }^{\mathrm{TM}}$ FC500 Flow Cytometer (Beckman Coulter, Miami, FL, USA). A minimum of 10,000 cells were analyzed for DNA content and the percentage of cell cycle phases was quantified.

Western blot analysis. Following drug treatment, cells were lysed in ice-cold whole cell extract buffer containing protease inhibitors. The lysate was agitated for $30 \mathrm{~min}$ at $4^{\circ} \mathrm{C}$ and centrifuged at 10,000 rpm for $10 \mathrm{~min}$. Protein concentration was measured using a BCA protein assay kit (Pierce, Rockford, IL, USA). Equal amounts of protein was subjected to electrophoresis using $12 \%$ sodium dodecyl sulfate-polyacrylamide gels. To verify equal protein loading and transfer, proteins were then transferred to polyvinylidene difluoride membranes and the membranes were blocked overnight at $4^{\circ} \mathrm{C}$ using blocking buffer [5\% non-fat dried milk in solution containing $50 \mathrm{mM}$ Tris/ $\mathrm{HCl}$ (pH 8.0), $2 \mathrm{mM} \mathrm{CaCl}_{2}, 80 \mathrm{mM}$ sodium chloride, $0.05 \%$ Tween-20 and $0.02 \%$ sodium azide]. Membranes were then incubated for $2 \mathrm{~h}$ at $25^{\circ} \mathrm{C}$ with specific primary antibodies followed by anti-rabbit or anti-mouse immunoglobulin $\mathrm{G}$ horseradish peroxidase-conjugated secondary antibodies. The membranes were washed three times for $10 \mathrm{~min}$ with washing solution. Finally, the protein bands were visualized on the X-ray film using an enhanced chemiluminescence detection system (Perkin-Elmer, Waltham, MA, USA).

Statistical analysis. Values are presented as the mean \pm SD The Student's t-test was used to analyze statistical significance.

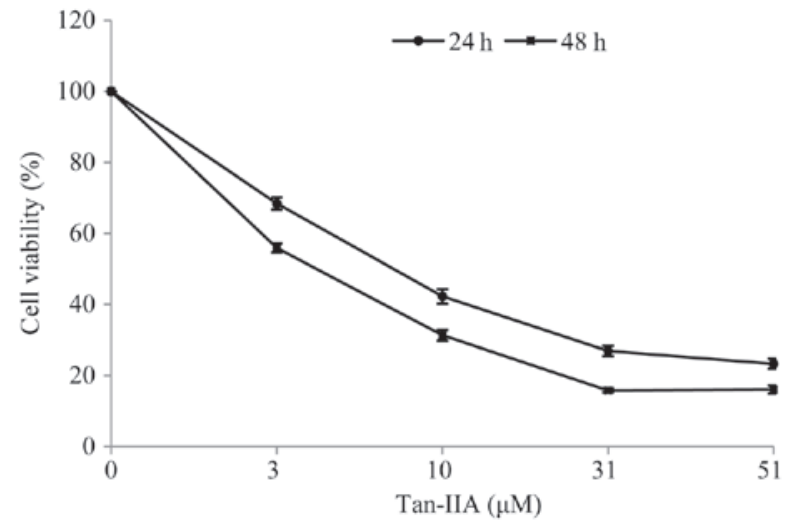

Figure 1. Cytotoxicity of Tan-IIA in BxPC-3 cells was determined using the MTT assay. Tan-IIA significantly inhibited BxPC-3 cell proliferation in a time- and dose-dependent manner. Results are presented as the mean \pm SD of three experiments. Tan-IIA, tanshinone IIA.

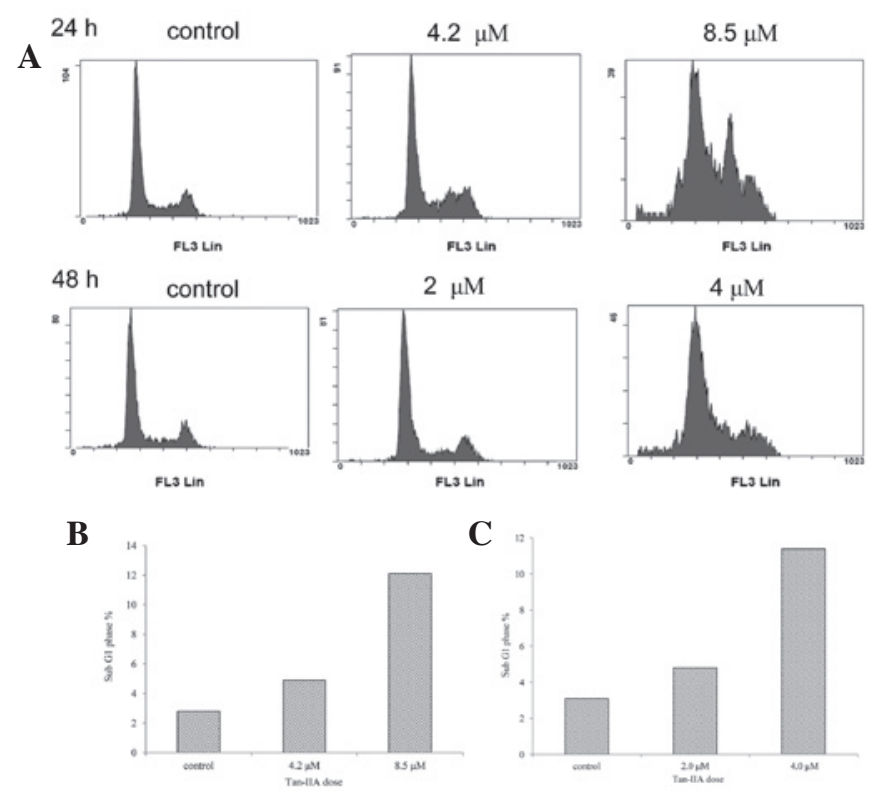

Figure 2. Cell cycle effect of Tan-IIA in BxPC-3 cells. Cells were treated with Tan-IIA $(0,4.2$ and $8.5 \mu \mathrm{M})$ for $24 \mathrm{~h}$ or Tan-IIA $(0,2$ and $4 \mu \mathrm{M})$ for $48 \mathrm{~h}$. (A) The cell cycle was analyzed by FACS. Results indicate that the percentages of sub- $\mathrm{G}_{1}$ cells were (B) $2.8,4.9$ and $12.1 \%$ for $24 \mathrm{~h}$, respectively; and (C) $3.1,4.8$ and $11.4 \%$ for $48 \mathrm{~h}$, respectively and demonstrate Tan-IIA induces apoptosis in a time- and dose-dependent manner. Tan-IIA, tanshinone IIA.

$\mathrm{P}<0.05$ was considered to indicate a statistically significant difference.

\section{Results and Discussion}

Cytotoxicity of Tan-IIA in BxPC-3 cells. When cultured with various concentrations of Tan-IIA $(0,3,10,31$ and $51 \mu \mathrm{M})$ for 24 and $48 \mathrm{~h}$, the viable cell percentages relative to the control were $68.41 \pm 1.69,42.3 \pm 2.02,26.91 \pm 1.47$ and $23.31 \pm 1.40 \%$ for $24 \mathrm{~h}$ and $55.90 \pm 1.20,31.32 \pm 1.54,15.83 \pm 0.56$ and $16.04 \pm 1.09 \%$ for $48 \mathrm{~h}$, respectively. During Tan-IIA treatment for 24 and $48 \mathrm{~h}$, the half-maximum inhibitory concentration $\left(\mathrm{IC}_{50}\right)$ was 8.5 and $4.0 \mu \mathrm{M}$, respectively. The results revealed that Tan-IIA inhibits the proliferation of human pancreatic cancer BxPC-3 cells in a time- and dose-dependent manner (Fig. 1). 
A
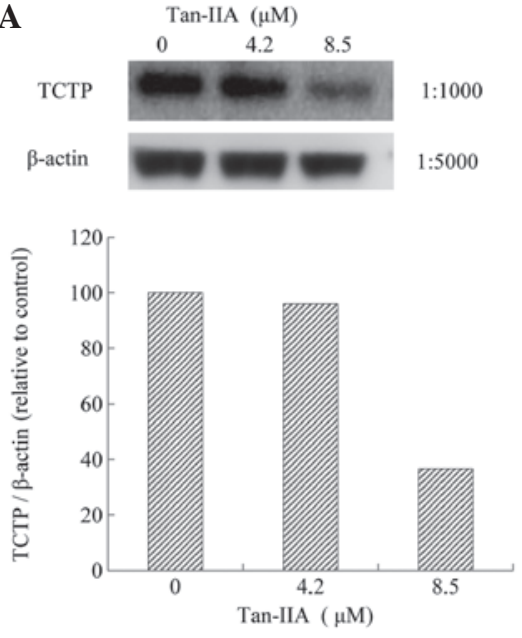

D
B
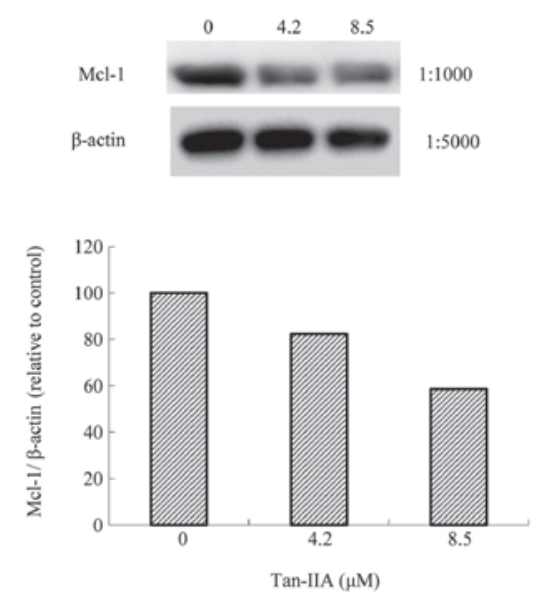

$\mathbf{E}$
C
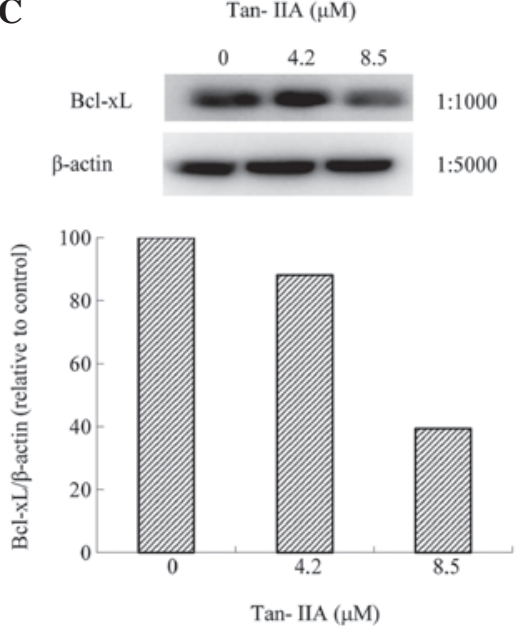
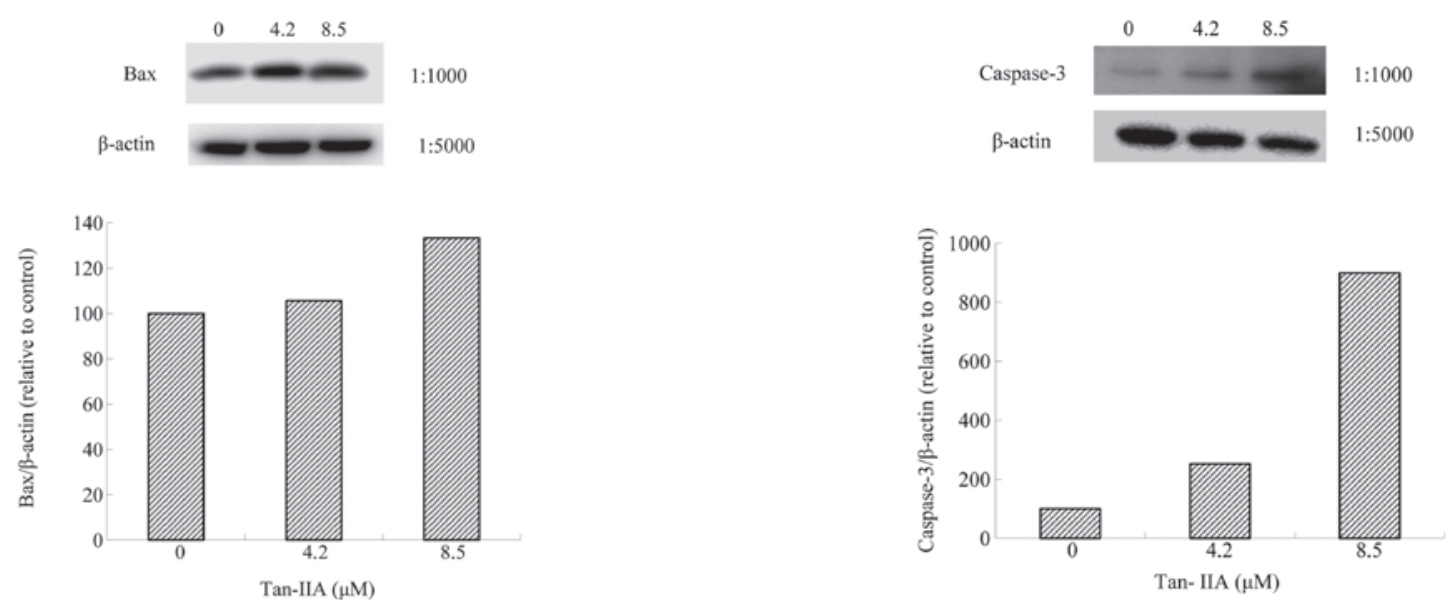

Figure 3. Protein expression of TCTP, MCL-1, Bcl-xL, Bax and Caspase-3 in BxPC-3 cells. Cells were treated with Tan-IIA (0, 4.2 and $8.5 \mu \mathrm{M})$ for $24 \mathrm{~h}$ and expression was evaluated by western blot analysis. Results revealed that Tan-IIA decreased expression of (A) TCTP, (B) Mcl-1 and (C) Bcl-xL and increased (D) Bax and (E) Caspase 3 expression. Tan-IIA, tanshinone IIA.

Tan-IIA induced apoptosis in BxPC-3 cells. BxPC-3 cells were plated in $6-\mathrm{cm}$ dishes at a density of $1 \times 10^{6}$ cells and treated with Tan-IIA $(0,4.2$ and $8.5 \mu \mathrm{M})$ for $24 \mathrm{~h}$. Cell cycle analysis was performed by FACS (Fig. 2A). Results indicate that the percentages of sub- $\mathrm{G}_{1}$ cells were $2.8,4.9$ and 12.1 , respectively (Fig. 2B). The BxPC-3 cells were plated in 6-cm dishes at a density of $1 \times 10^{6}$ cells and then were treated with Tan-IIA $(0,2$ and $4 \mu \mathrm{M}$ ) for $48 \mathrm{~h}$. Percentages of sub- $\mathrm{G}_{1}$ cells were 3.1, 4.8 and $11.4 \%$, respectively (Fig. 2C). These results demonstrate that Tan-IIA induces apoptosis in a time- and dose-dependent manner.

Effect of Tan-IIA on protein expression of TCTP, MCL-1, Bcl-xl, Bax and Caspase-3 in BxPC-3 cells. BxPC-3 cells were treated with various concentrations $(0,4.2$ and $8.5 \mu \mathrm{M})$ of Tan-IIA for $24 \mathrm{~h}$ and the protein expression levels were evaluated by western blot analysis. The results revealed that Tan-IIA decreased expression of TCTP (Fig. 3A), MCL-1 (Fig. 3B) and Bcl-xl (Fig. 3C) and increased Bax (Fig. 3D) and Caspase-3 expression (Fig. 3E).

BxPC-3 cells were treated with various concentrations $(0$, 2.0 and $4.0 \mu \mathrm{M}$ ) of Tan-IIA for $48 \mathrm{~h}$ and protein expression was evaluated by western blot analysis. Tan-IIA decreased expres- sion of TCTP (Fig. 4A), MCL-1 (Fig. 4B) and Bcl-xl (Fig. 4C) and increased Bax (Fig. 4D) and Caspase-3 expression (Fig. 4E).

BxPC-3 cells were treated with Tan-IIA $(8.5 \mu \mathrm{M})$ for various durations $(0,24,48$ and $72 \mathrm{~h})$ and protein expression levels were evaluated by western blot analysis. Tan-IIA decreased expression of TCTP (Fig. 5A), MCL-1 (Fig. 5B) and Bcl-xl (Fig. 5C) and increased Bax (Fig. 5D) and Caspase-3 expression (Fig. 5E). Results demonstrate that Tan-IIA treatment of BxPC-3 cells inhibited TCTP, Bcl-xl and MCL-1 expression.

TCTP is a $18-23-\mathrm{kDa}$ hydrophilic protein, identified over 30 years ago in Ehrlich acites tumor cells (12-14). Overexpression of TCTP inhibits apoptosis and previous studies using antisense and siRNA knockdown identified increased apoptosis following knockdown of TCTP (15-17). It is well known that TCTP binds MCL-1 $(16,18,19)$ and Bcl-xL $(20)$ to inhibit apoptosis. In addition, the anti-apoptotic mechanism of TCTP has also been associated with antagonization of Bax (21). Tan-IIA also downregulates expression of the mitochondrial protective Bcl-2 family memeber MCL-1, inducing apoptosis in prostate cancer cells (22). These observations indicate that Tan-IIA inhibits protein expression of TCTP, MCL-1 and Bcl-xl to destroy mitochondrial function and increase Bax and Caspase-3 expression, inducing apoptosis in human pancreatic 
A
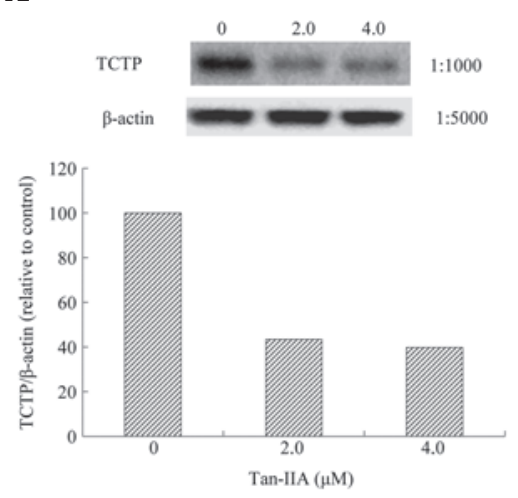

D
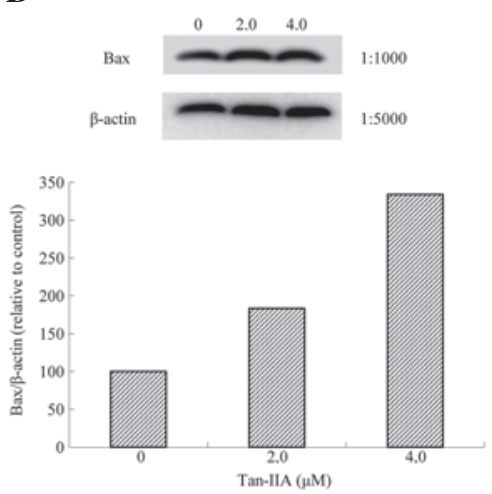
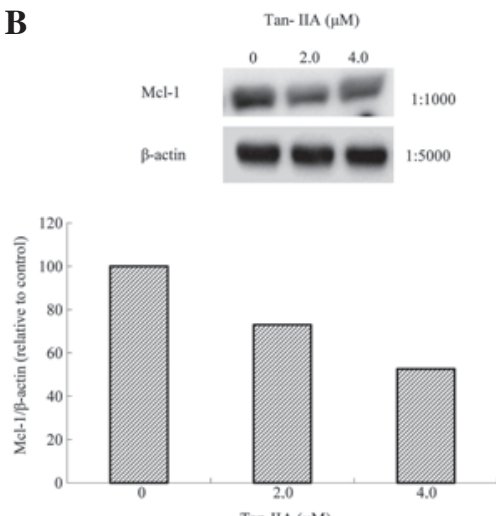

C
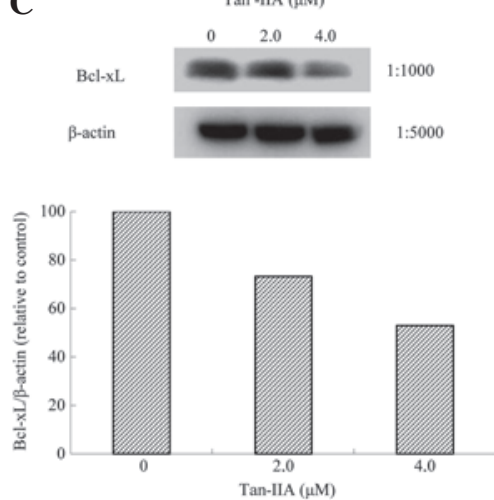

$\mathbf{E}$

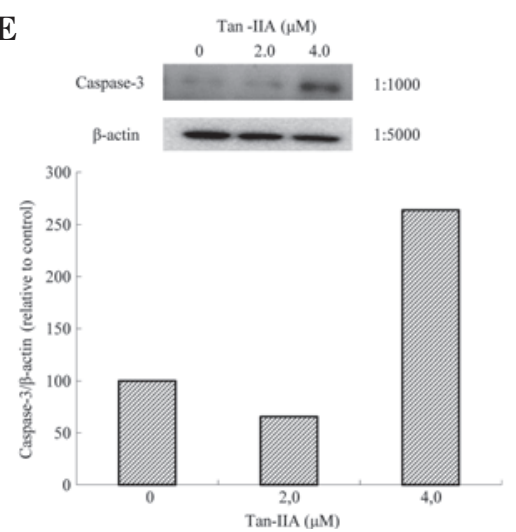

Figure 4. Protein expression levels of TCTP, MCL-1, Bcl-xL, Bax and Caspase-3 in BxPC-3 cells. Cells were treated with Tan-IIA (0, 2.0 and $4.0 \mu \mathrm{M})$ for 48 h and expression was evaluated by western blot analysis. Results demonstrate that Tan-IIA decreased expression of (A) TCTP, (B) Mcl-1 and (C) Bcl-xL and increased (D) Bax and (E) Caspase-3 expression. Tan-IIA, tanshinone IIA.

A

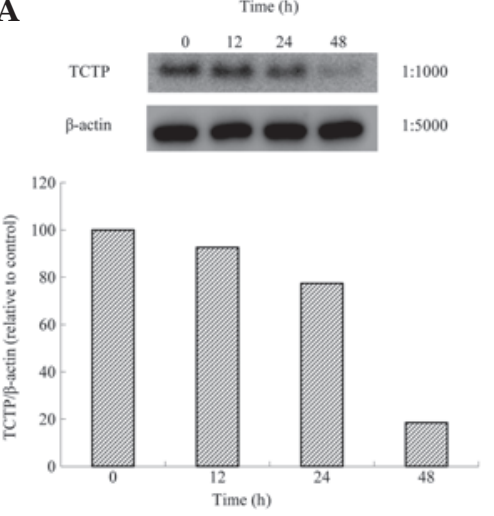

D
B
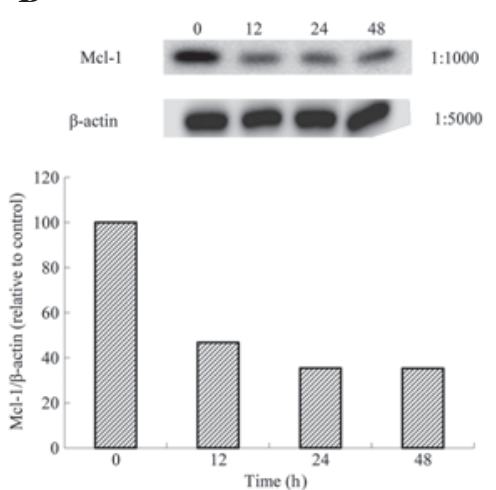

C
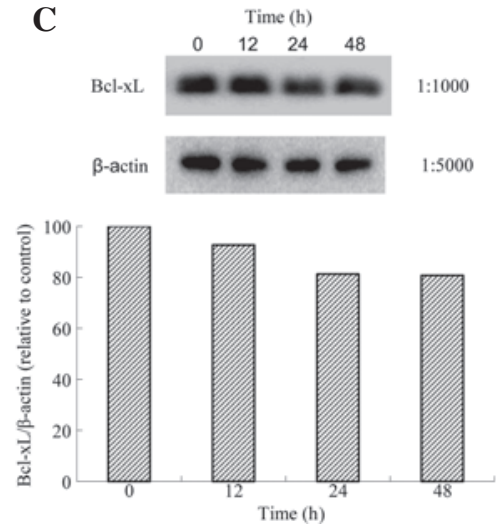

$\mathbf{E}$
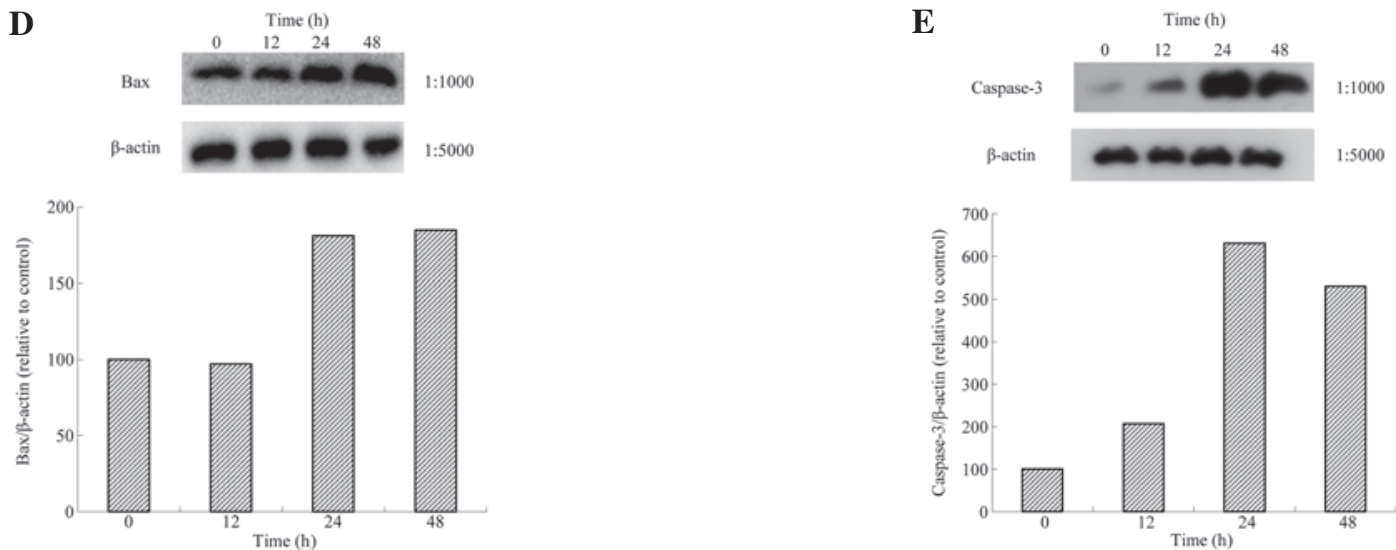

Figure 5. Protein expression levels of TCTP, Mcl-1, Bcl-xL, Bax and Caspase-3 in BxPC-3 cells. Cells were treated with Tan-IIA (8.5 $\mu$ M) for various durations $(0,24,48$ and $72 \mathrm{~h}$ ) and expression was evaluated by western blot analysis. Results revealed that Tan-IIA decreased expression (A) TCTP, (B) Mcl-1 and (C) Bcl-xL and increased (D) Bax and (E) Caspase-3 expression. Tan-IIA, tanshinone IIA. 
cancer BxPC-3 cells in vitro. The current study is the first to demonstrate inhibition of BxPC-3 cells by Tan-II through downregulation of TCTP, Bcl-xl and MCL-1 expression. The chemotherapeutic potential of Tan-IIA in human pancreatic cancer requires additional studies in the future.

\section{Acknowledgements}

The present study was supported by a grant from the Research Section of the Changhua Christian Hospital (Changhua, Taiwan; no. 101-CCH-IRP-11).

\section{References}

1. Jemal A, Bray F, Center MM, et al: Global cancer statistics. CA Cancer J Clin 61: 69-90, 2011.

2. Siegel R, Naishadham D and Jemal A: Cancer statistics, 2012. CA Cancer J Clin 62: 10-29, 2012.

3. Verhoef MJ, Balneaves LG, Boon HS and Vroegindewey A: Reasons for and characteristics associated with complementary and alternative medicine use among adult cancer patients: a systematic review. Integr Cancer Ther 4: 274-286, 2005.

4. Che AJ, Zhang JY, Li CH, Chen XF, Hu ZD and Chen XG: Separation and determination of active components in Radix Salviae miltiorrhizae and its medicinal preparations by nonaqueous capillary electrophoresis. J Sep Sci 27: 569-575, 2004.

5. Zhou L, Zuo Z and Chow MS: Danshen: an overview of its chemistry, pharmacology, pharmacokinetics and clinical use. J Clin Pharmacol 45: 1345-1359, 2005.

6. Su CC and Lin YH: Tanshinone IIA downregulates the protein expression of ErbB-2 and upregulates TNF- $\alpha$ in colon cancer cells in vitro and in vivo. Int J Mol Med 22: 847-851, 2008.

7. Su CC and Lin YH: Tanshinone IIA inhibits human breast cancer cells through increased Bax to Bcl-xL ratios. Int J Mol Med 22: 357-361, 2008.

8. Chiu TL and Su CC: Tanshinone IIA induces apoptosis in human lung cancer A549 cells through the induction of reactive oxygen species and decreasing the mitochondrial membrane potential. Int J Mol Med 25: 231-236, 2010.

9. Cheng CY and Su CC: Tanshinone IIA may inhibit the growth of small cell lung cancer $\mathrm{H} 146$ cells by up-regulating the Bax/Bcl-2 ratio and decreasing mitochondrial membrane potential. Mol Med Rep 3: 645-650, 2010.
10. Cheng CY and Su CC: Tanshinone IIA inhibits Hep-J5 cells by increasing calreticulin, Caspase-12 and GADD153 protein expression. Int J Mol Med 26: 379-385, 2010.

11. Fronza M, Murillo R, Ślusarczyk S, et al: In vitro cytotoxic activity of abietane diterpenes from Peltodon longipes as well as Salvia miltiorrhiza and Salvia sahendica. Bioorg Med Chem 19: 4876-4881, 2011.

12. Chitpatima ST,Makrides S, Bandyopadhyay R and Brawerman G: Nucleotide sequence of a major messenger RNA for a 21 kilodalton polypeptide that is under translational control in mouse tumor cells. Nucleic Acids Res 16: 2350, 1988.

13. Bommer UA, Lazaris-Karatzas A, De Benedetti A, et al: Translational regulation of the mammalian growth-related protein P23: involvement of eIF-4E. Cell Mol Biol Res 40: 633-641, 1994.

14. Yenofsky R, Cereghini S, Krowczynska A and Brawerman G: Regulation of mRNA utilization in mouse erythroleukemia cells induced to differentiate by exposure to dimethyl sulfoxide. Mol Cell Biol 3: 1197-1203, 1983.

15. Li F, Zhang D and Fujise K: Characterization of fortilin, a novel antiapoptotic protein. J Biol Chem 276: 47542-47549, 2001.

16. Zhang D, Li F, Weidner D, Mnjoyan ZH and Fujise K: Physical and functional interaction between myeloid cell leukemia 1 protein (MCL1) and Fortilin. The potential role of MCL1 as a fortilin chaperone. J Biol Chem 277: 37430-37438, 2002.

17. Tuynder M, Susini L, Prieur S, et al: Biological models and genes of tumor reversion: cellular reprogramming through tpt1/ TCTP and SIAH-1. Proc Natl Acad Sci USA 99: 14976-14981, 2002.

18. Graidist P, Phongdara A and Fujise K: Antiapoptotic protein partners fortilin and MCL1 independently protect cells from 5-fluorouracil-induced cytotoxicity. J Biol Chem 279: 40868-40875, 2004

19. Liu H, Peng HW, Cheng YS, Yuan HS and Yang-Yen HF: Stabilization and enhancement of the antiapoptotic activity of mcl-1 by TCTP. Mol Cell Biol 25: 3117-3126, 2005.

20. Yang Y, Yang F, Xiong Z, et al: An N-terminal region of translationally controlled tumor protein is required for its antiapoptotic activity. Oncogene 24: 4778-4788, 2005.

21. Susini L, Besse S, Duflaut D, et al: CTP protects from apoptotic cell death by antagonizing bax function. Cell Death Differ 15: 1211-1220, 2008

22. Won SH, Lee HJ, Jeong SJ, et al: Tanshinone IIA induces mitochondria dependent apoptosis in prostate cancer cells in association with an inhibition of phosphoinositide 3-kinase/AKT pathway. Biol Pharm Bull 33: 1828-1834, 2010. 